\title{
Electrometric Measurement of Plasma, Erythrocyte, and Whole Blood Cholinesterase Activities in Healthy Human Volunteers
}

\author{
F. K. Mohammad, BVMS, MS, PhDa, A. S. Alias, BVMS, MSca, O. A. H. Ahmed, BSc, Pharm, MSc ${ }^{b}$ \\ aCollege of Veterinary Medicine \\ bCollege of Pharmacy, University of Mosul, Mosul, Iraq
}

\begin{abstract}
Introduction: The measurement of blood cholinesterase activity is a useful tool for monitoring exposure to organophosphate and carbamate insecticides. Blood cholinesterase activity is measured colorimetrically or electrometrically. Recently, a simple and practical electrometric method has been described and validated for measuring blood cholinesterase activity in people and animals. The purpose of the present report was to use the modified electrometric technique for measuring blood (plasma, erythrocyte and whole blood) cholinesterase activities in apparently healthy human volunteers in Mosul, Iraq.

Method: Cholinesterase activities in the plasma, erythrocytes, and whole blood of healthy male $(n=72)$ and female $(n=31)$ volunteers were measured by an electrometric method; the method involved the addition of $0.2 \mathrm{ml}$ of blood sample to $3 \mathrm{ml}$ of distilled water followed by $3 \mathrm{ml}$ of barbital-phosphate buffer solution ( $\mathrm{pH}$ 8.1). The $\mathrm{pH}(\mathrm{pH} 1)$ of the mixture was measured, and then $0.1 \mathrm{ml}$ of $7.5 \%$ of acetylcholine iodide, as a substrate, was added. The reaction mixture was incubated at $37^{\circ} \mathrm{C}$ for 20 minutes. The $\mathrm{pH}(\mathrm{pH} 2)$ of the reaction mixture was measured after the end of the incubation period. Enzyme activity was expressed as $\Delta \mathrm{pH} / 20 \mathrm{~min}=\mathrm{pH} 1-$ $\mathrm{pH} 2-(\Delta \mathrm{pH}$ of the blank). The blank was without the blood sample. Following in vitro inhibition of pseudo cholinesterase by quinidine sulfate, true cholinesterase activity was estimated in the plasma of the subjects. After in vitro addition of the organophosphate (chlorpyrifos and methidathion, 0.5 and $1 \mu \mathrm{M}$ ) and carbamate (carbaryl, 5 and $10 \mu \mathrm{M}$ ) insecticides to the reaction mixtures, inhibitions of blood cholinesterases were measured.

Results: Mean reference cholinesterase activities $(\Delta \mathrm{pH} / 20 \mathrm{~min})$ in the plasma, erythrocytes, and whole blood of male subjects were $0.98,1.39$, and 1.41 , respectively. Females were $0.85,1.22$, and 1.23 , respectively. Ten minutes after in vitro addition of quinidine sulfate to inhibit pseudo cholinesterase activity in the plasma, the estimated true cholinesterase activities in males and females were 0.08 and $0.07 \Delta \mathrm{pH} / 20 \mathrm{~min}$, respectively. The percentage of true cholinesterase in the plasma of males and females was 8.2. Using the modified electrometric method, various percentages of cholinesterase inhibitions in the plasma, erythrocytes, and whole blood were detected after in vitro addition of the organophosphate insecticides (chlorpyrifos and methidathion) and the carbamate insecticide (carbaryl) to the reaction mixtures.

Conclusions: These findings are the first collective report of human plasma, erythrocyte, and whole blood cholinesterase activities as determined by the modified electrometric method, and they could serve as reference points for future studies that involve human exposure to anticholinesterase pesticides.
\end{abstract}

Keywords: cholinesterase, organophosphate, carbaryl, electrometric method

Notes: This study was supported by a grant from Stony Brook University, Environmental Health HEAD Program, Iraq (Minigrant Projects).

Acknowledgments: The authors thank Prof. Dr. Wajdy Hailoo, Head of Division of Occupational and Environmental Medicine at Stony Brook University for his support throughout the project.

Corresponding Author: Prof. Dr. F. K. Mohammad, University of Mosul, P.O. Box 11136, Mosul, Iraq. Phone: (964) 770-160-5334. Email: fouadmohammad@yahoo.com 


\section{INTRODUCTION}

Organophosphate and carbamate insecticides are widely used in public health, veterinary practice, and in agriculture [1-3]. They pose major environmental pollution problems and health hazards to people and animals [1-6]. These insecticides inhibit cholinesterase (ChE) activity in the nervous tissues and neuromuscular junctions, causing an accumulation of acetylcholine at the nerve endings which subsequently produces signs of toxicosis characterized by nicotinic, muscarinic, and central nervous system effects [1,7-9].

The measurement of blood (plasma, serum, erythrocyte, or whole blood) ChE activities is a useful tool for monitoring exposure to organophosphate and carbamate insecticides and in diagnosing poisonings $[1,7,10,11]$. A $20-30 \%$ decrease in serum or plasma ChE activity usually suggests exposure to anti-ChE compounds $[10,11]$. Inhibition of blood ChE activity by more than $50 \%$ supports the diagnosis of poisoning and indicates a serious adverse health condition that needs immediate attention $[5,7,10,11]$.

Various colorimetric and electrometric (potentiometric) methods are available to determine blood cholinesterase activity $[7,12,13]$. One of the main methods for measuring blood cholinesterase activity is the electrometric method: it is based on the hydrolysis of acetylcholine and the production of acetic acid that subsequently decreases the $\mathrm{pH}$ of the reaction mixture $[7,12,13]$. The original electrometric method of Michel is most commonly used in people $[7,12,13,14]$. However, the shortcomings of the Michel's electrometric method are relative insensitivity, sample size, long incubation period, and low throughput [7,12-14]. In addition, the original electrometric method is not preferred for detection of ChE inhibition induced by carbamates [15-17]. Carbamylated ChE is unstable in the reaction mixture of the electrometric method of Michel because of considerable sample dilution and a long assay time of more than 60 minutes [15-17].

Various modifications of the electrometric method have been described for measuring plasma or erythrocyte ChE activities in clinical and research applications [7,13,18-20]. These modifications include increasing sample volume, increasing or decreasing incubation time, increasing incubation temperature, or using buffers of different compositions. Recently, a simple modification of the electrometric method has been reported; it was originally modified from a rapid electrometric method described in sheep $[20,19]$. By omitting apparently unnecessary steps of saline washing of the erythrocytes and the one or two incubation periods of 10 minutes each before substrate addition, the modified method was advocated for its one-step short incubation time (20 minutes), the use of a single barbital-phosphate buffer, and the overall shorter assay time $[19,20]$. The modified method has been validated in people and several animal species [20-25]. Further, the modified method (in contrast to the original electrometric method of Michel) can detect ChE inhibition caused by carba- mate insecticides such as carbaryl and methomyl [14,20-22]. In measuring ChE activity, the modified method correlates well with the electrometric method of Michel and the spectrophotometric method of Ellman $[19,23]$. Other than a single validation report, no attempt has been made to use the modified method for measuring ChE activity in people [20]. Therefore, the purpose of our study was to apply the modified electrometric method for measuring blood ChE activities in apparently healthy human volunteers in Mosul, Iraq $[19,20]$. This is an initial attempt, since diagnostic interpretation of ChE data requires knowledge of a normal reference range ChE values $[5,7,10,11,14]$.

\section{METHODS}

Human volunteers included in the study were apparently healthy subjects: 72 males, mean ( \pm SD) age of $32 \pm 8$ years, and 31 females, mean $( \pm \mathrm{SD})$ age of $32 \pm 11$ years. Volunteers had no history of exposure to anti ChE insecticides for at least two months before blood sampling. Exclusion criteria for ruling out exposure to insecticides were based on subjects non-involvement in any activity related to handling and/or exposure to insecticides. The subjects were from Mosul, Iraq. Informed consents were obtained from the volunteers before the start of the study. Institutional Review Board approval was also obtained before the study.

\section{Electrometric Method for Measurement of Plasma, Erythrocyte and Whole Blood ChE Activity}

From September 2005 to February 2006, we used heparinized test tubes to obtain venous blood samples from volunteers [26]. Plasma was separated from erythrocytes by centrifugation at 3000 rpm (Centurion, U.K.) for 15 minutes. We used a modified electrometric method validated for use in people $[19,20]$ (Figure 1). For a typical assay condition, the reaction mixture in a $10-\mathrm{ml}$ beaker contained $3 \mathrm{ml}$ distilled water, $0.2 \mathrm{ml}$ plasma, erythrocytes or whole blood, and $3 \mathrm{ml} \mathrm{pH} 8.1$ barbital-phosphate buffer [19]. The $\mathrm{pH}$ of the mixture ( $\mathrm{pH} 1)$ was measured with a glass electrode using a pH meter (Hanna Instruments, Romania) before $0.1 \mathrm{ml}$ of aqueous solution of the substrate acetylcholine iodide (7.5\%) was added to the reaction mixture that was incubated at $37^{\circ} \mathrm{C}$ for 20 minutes. At the end of the incubation period, we measured the $\mathrm{pH}$ of the reaction mixture $(\mathrm{pH} 2)$. The enzyme activity was calculated as follows:

- $\operatorname{ChE}$ activity $(\Delta \mathrm{pH} / 20$ minutes $)=(\mathrm{pH} 1-\mathrm{pH} 2)-\Delta \mathrm{pH}$ of blank

The blank was without the blood aliquot. The barbital-phosphate buffer solution consisted of $1.24 \mathrm{~g}$ sodium barbital (BDH), $0.63 \mathrm{~g}$ potassium dihydrogen phosphate (Merck, Germany), and 35.07 g sodium chloride (BDH) dissolved in one liter of distilled water [19]. The $\mathrm{pH}$ of the buffer was adjusted to 8.1 with $1 \mathrm{~N} \mathrm{HCl}$. 


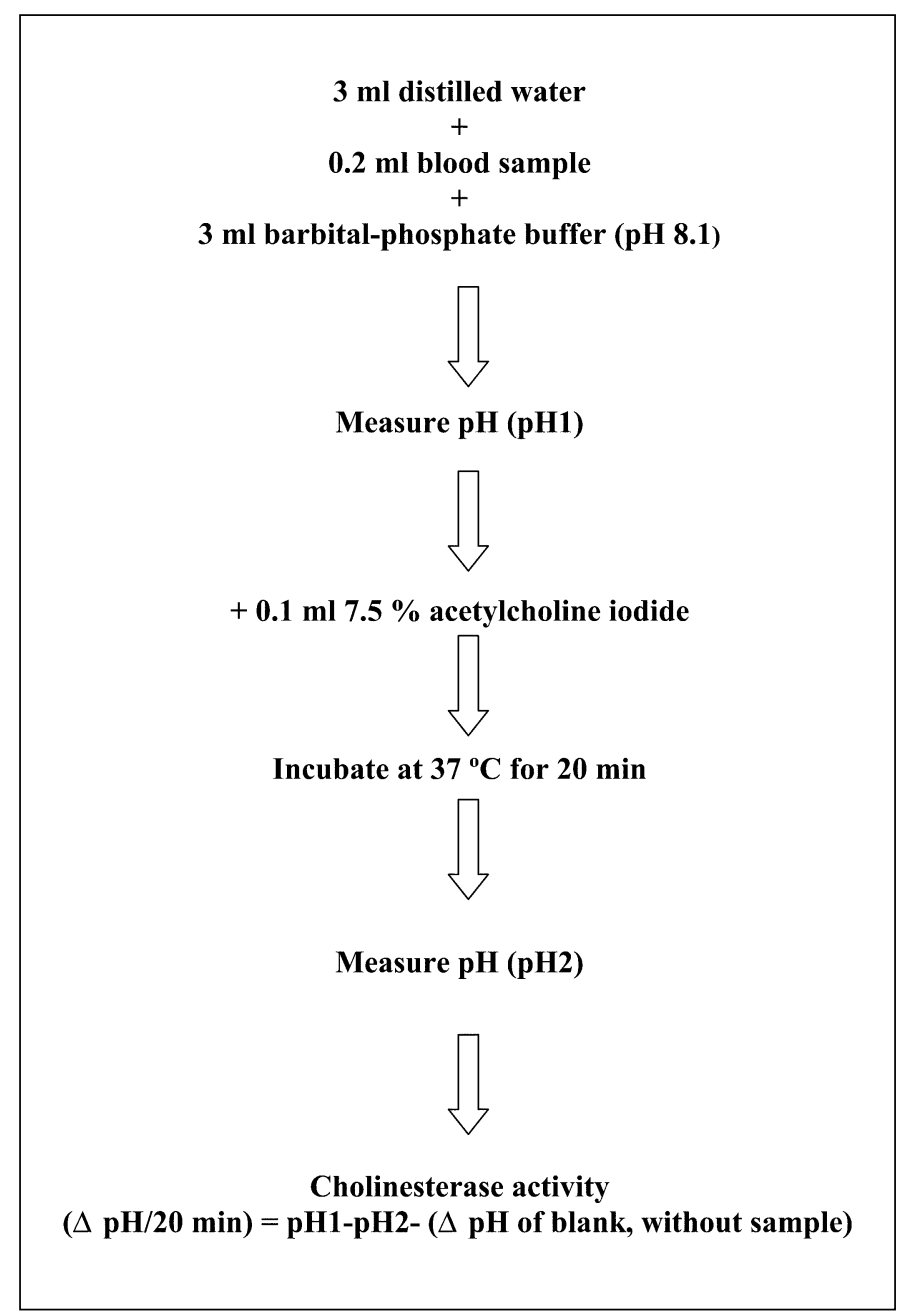

Figure 1: Steps for the Determination of Blood Cholinesterase Activity by a Modified Electrometric Method.

\section{Measurement of True ChE Activity in the Plasma}

Aliquots $(0.2 \mathrm{ml})$ of the volunteers' plasma samples were incubated in separate reaction mixtures with $40 \mu \mathrm{l}$ of $0.1 \%$ quinidine sulfate (Sigma, St. Louis, USA) for $10 \mathrm{~min}$ at $37^{\circ} \mathrm{C}$ to inhibit pseudo ChE activity $[19,20]$. Thereafter, the remaining (true ChE) activity in the plasma was measured. Pseudo ChE activity $=\mathrm{ChE}$ activity (without quinidine) - true ChE activity (with quinidine). Quinidine specifically inhibits pseudo ChE activity in the plasma $[6,7]$.

\section{In vitro ChE Inhibition by Organophosphate (Chlorpyrifos and Methidathion) and Carbamate (Carbaryl) Insecticides}

Pooled plasma, erythrocyte, and whole blood samples were collected from 6 male volunteers. The method of inhibitor-ChE incubation was used to cause in vitro inhibition of ChE activities in the blood sample by chlopyrifos (40\%, VAPCO, Jordan) and methidathion (50\%, Agricultural Chemicals Manufacturing Enterprise, Jordan) and by carbaryl (85\%, Sociedad Anonima De Agroquimicos, Spain) $[19,20]$. The insecticides were prepared in distilled water and individually added in a volume of $0.1 \mathrm{ml}$ to the reaction mixtures of the plasma, erythrocytes, or whole blood. The final reaction volumes in control and inhibited samples remained the same $(6.3 \mathrm{ml})$ by using $2.9 \mathrm{ml}$ of distilled water instead of $3 \mathrm{ml}$ (Figure 1). The final concentrations of chlopyrifos and methidathion in the reaction mixtures were 0.5 and $1 \mu \mathrm{M}$; final concentrations of carbaryl were 5 and $10 \mu \mathrm{M}$. Control reaction mixtures did not contain any insecticide, and they were used for measurement of base-line ChE values. The reaction mixtures were incubated at $37^{\circ} \mathrm{C}$ for 10 minutes $[19,20]$. Thereafter, the residual ChE activity in the mixtures was measured as before. The $\%$ of enzyme inhibition was calculated as follows:

- \% ChE inhibition=

[ChE activity (without insecticide)-ChE activity (with insecticide)/

ChE activity (without insecticide)] X 100

\section{Statistics}

The samples sizes were determined using the Altman's nomogram, taking into account the suitability of subject numbers within the groups for statistical evaluation (e.g. sex, blood fractions, and ChE inhibition) [27]. We determined the mean, standard deviation, range, and 95\% confidence interval of plasma, erythrocyte, and whole blood ChE activities [27]. When applicable, the data were subjected to one way analysis of variance followed by the least significant difference test [27]. Student's-t-test was used for the means of two groups [27]. The level of significance was at $\mathrm{P}<0.05$.

\section{RESULTS}

Tables 1 and 2 show the mean, 95\% confidence interval, and related statistics for plasma, erythrocyte, and whole blood ChE activities in apparently healthy male and female subjects. Mean reference ChE activities ( $\Delta \mathrm{pH} / 20 \mathrm{~min}$ ) in the plasma, erythrocytes, and whole blood of male subjects were $0.98,1.39$ and 1.41 , respectively (Table 1$)$. Mean reference ChE activities $(\Delta \mathrm{pH} / 20$ min) in the plasma, erythrocytes, and whole blood of the females were $0.85,1.22$ and 1.23, respectively (Table 2). Plasma ChE activities of male and female subjects were significantly lower than those of the erythrocytes and whole blood (Tables 1 and 2).

Ten minutes after in vitro addition of quinidine sulfate to inhibit pseudo ChE activity in the plasma, the estimated mean true ChE activities in male and female subjects were 0.08 and $0.07 \Delta \mathrm{pH} / 20 \mathrm{~min}$, respectively (Table 3). The percentage of true ChE activity in the plasma of the male and female subjects was 8.2 (Table 4). 
Table 1. Normal Cholinesterase Activities $(\Delta \mathrm{pH} / 20$ minutes) in the Plasma, Erythrocytes, and Whole Blood of Male Subjects

\begin{tabular}{lccc}
\hline Parameter & Plasma & Erythrocyte & Whole blood \\
\hline $\mathrm{n}$ & 72 & 72 & 72 \\
\hline Mean & 0.98 & $1.39^{*}$ & $1.41^{*}$ \\
\hline Standard deviation & 0.242 & 0.247 & 0.172 \\
\hline Range (min-max) & $0.52-1.66$ & $0.79-2.02$ & $0.94-1.83$ \\
\hline $95 \%$ confidence interval & $0.92,1.04$ & $1.33,1.45$ & $1.37,1.45$
\end{tabular}

*Significantly different from the value of plasma cholinesterase activity, $P<0.05$.

Table 2. Normal Cholinesterase Activities $(\Delta \mathrm{pH} / 20$ minutes) in the Plasma, Erythrocytes, and Whole Blood of Female Subjects

\begin{tabular}{lccc}
\hline Parameter & Plasma & Erythrocyte & Whole blood \\
\hline $\mathrm{n}$ & 31 & 31 & 31 \\
\hline Mean & 0.85 & $1.22^{*}$ & $1.23^{*}$ \\
\hline Standard deviation & 0.282 & 0.309 & 0.252 \\
\hline Range (min-max) & $0.30-1.44$ & $0.60-1.92$ & $0.80-1.66$ \\
\hline $95 \%$ confidence interval & $0.75,0.95$ & $1.11,1.33$ & $1.14,1.32$ \\
\hline
\end{tabular}

*Significantly different from the value of plasma cholinesterase activity, $P<0.05$.

Table 3. True Cholinesterase Activity $(\Delta \mathrm{pH} / 20 \mathrm{~min}$ utes) in the Plasma of Male and Female Subjects

\begin{tabular}{lcc}
\hline Parameter & Males & Females \\
\hline $\mathrm{n}$ & 72 & 31 \\
\hline Mean & 0.08 & 0.07 \\
\hline Standard deviation & 0.033 & 0.031 \\
\hline Range (min-max) & $0.01-0.15$ & $0.02-0.15$ \\
\hline $95 \%$ confidence interval & $0.07,0.09$ & $0.06,0.08$ \\
\hline
\end{tabular}

Quinidine sulfate was used to inhibit pseudo cholinesterase activity in the plasma.

The insecticides (chlorpyrifos, methidathion, and carbaryl) in a concentration-dependent manner variably inhibited plasma, erythrocyte, and whole blood ChE activities in vitro (Table 5).

\section{DISCUSSION}

Our research introduces (for the first time in a collective manner) normal ChE activities of the plasma, erythrocyte, and whole blood of apparently healthy male and female volunteers in Mosul (Iraq) as determined by a simple modified electrometric method. These values could serve as preliminary reference values for future studies using the modified electrometric method for rapid measurement of blood ChE activities. Measurement of blood ChE activity in people is a non-invasive biomarker method for monitoring poisoning or exposure to organophosphate and carbamate insecticides $[6,7,10,11,14]$. These results further support and expand our previous findings, and the modified method was validated for determining ChE activities in the plasma and erythrocytes of people [20]. Furthermore, the modified method has been applied successfully to evaluate poisoning induced by organophosphate and carbamate insecticides in several animal species [20-25].

The short 20-minute one-step incubation time and the $0.2 \mathrm{ml}$ sample volume of the blood appeared to be suitable for the assay conditions necessary to produce enzyme activity without interfering with the buffering capacity in the reaction mixture. This is in agreement with our earlier findings in people and animals $[19-25,28]$. Compared to the incubation period (more than 60 minutes) of the Michel's method, the one-step short incubation time of the modified method would be useful in increasing the rapidity of the procedure for multiple samples [14]. The modified method also substantially decreases the handling of the reaction mixture as found in other electrometric methods $[7,13,14,18]$. By using a glass electrode, it also eliminates the problem of color interference found in the spectrophotometric methods $[7,12]$. In addition, the procedure is inexpensive, like that of the Michel's, because it uses commonly available laboratory equipment and reagents.

The modified method was also used to estimate true ChE activity in the plasma of the subjects. The reported values in the present study correlate with those reported in studies by others [5-7]. True ChE activity in the plasma of mammals ranges between 10 to $30 \%[5-7,20]$. Activity is much lower than those of wild birds $[6,7,24]$. Organophosphate or carbamate pesticides may inhibit true ChE in different ways $[1,6-8,10]$.

There were physiological differences in the values of plasma ChE and those of the erythrocyte and whole blood. Such differences have been reported earlier, and they might contribute to the differential responses of ChEs to organophosphates and carbamates $[1,6,7,11]$.

In vitro inhibition of plasma, erythrocyte, and whole blood ChE activities by chlorpyrifos, methidation (organophosphates), and by carbaryl (a carbamate) is in agreement with the reported anti ChE actions of these insecticides $[1,3,16,20]$. These results and previous in vitro and in vivo ChE inhibition studies suggest the sensitivity of the modified method in detecting ChE inhibition caused by organophosphates and possibly carbamates $[19,20-23,25]$. 
Table 4. Estimated Percentages of True Cholinesterase (ChE) Activity in the Plasma of Male and Female Subjects

\begin{tabular}{|c|c|c|c|c|}
\hline \multirow{2}{*}{$\begin{array}{l}\text { Plasma ChE activity } \\
(\Delta \mathrm{pH} / 20 \text { minutes })\end{array}$} & \multicolumn{2}{|c|}{ Male $(n=72)$} & \multicolumn{2}{|c|}{ Female $(n=31)$} \\
\hline & Mean \pm SD & Percent activity & Mean \pm SD & Percent activity \\
\hline Total ChE & $0.98 \pm 0.242$ & 100 & $0.85 \pm 0.282$ & 100 \\
\hline True ChE* & $0.08 \pm 0.033$ & 8.2 & $0.07 \pm 0.031$ & 8.2 \\
\hline
\end{tabular}

\section{CONCLUSIONS}

Our study reports, in an initial attempt, normal range values of plasma, erythrocyte, and whole blood ChE activities in male and female volunteers as determined by a simple electrometric method. These values could serve as reference points for future studies concerned with the biomonitoring of human exposure to anti ChE pesticides.

The authors have no potential conflicts of interest to report.

\section{REFERENCES}

1. Wilson BW. Cholinesterase inhibitors. In: Wexler P (ed.) Encyclopedia of toxicology. Vol. 1. San Diego, CA: Academic Press, 1998: 326-340.

2. Coggon D. Work with pesticides and organophosphate sheep dips. Occup Med (London) 2002; 52: 467-470.

3. Jaga K; Dhamani C. Sources of exposure to and public health implications of organophosphate pesticides. Rev Panam Salud Publica 2003; 14: 171-185.

Table 5: In vitro Inhibition of Human Plasma, Erythrocyte, and Whole Blood Cholinesterase (ChE) Activities by Chlorpyrifos, Methidathion, and Carbaryl

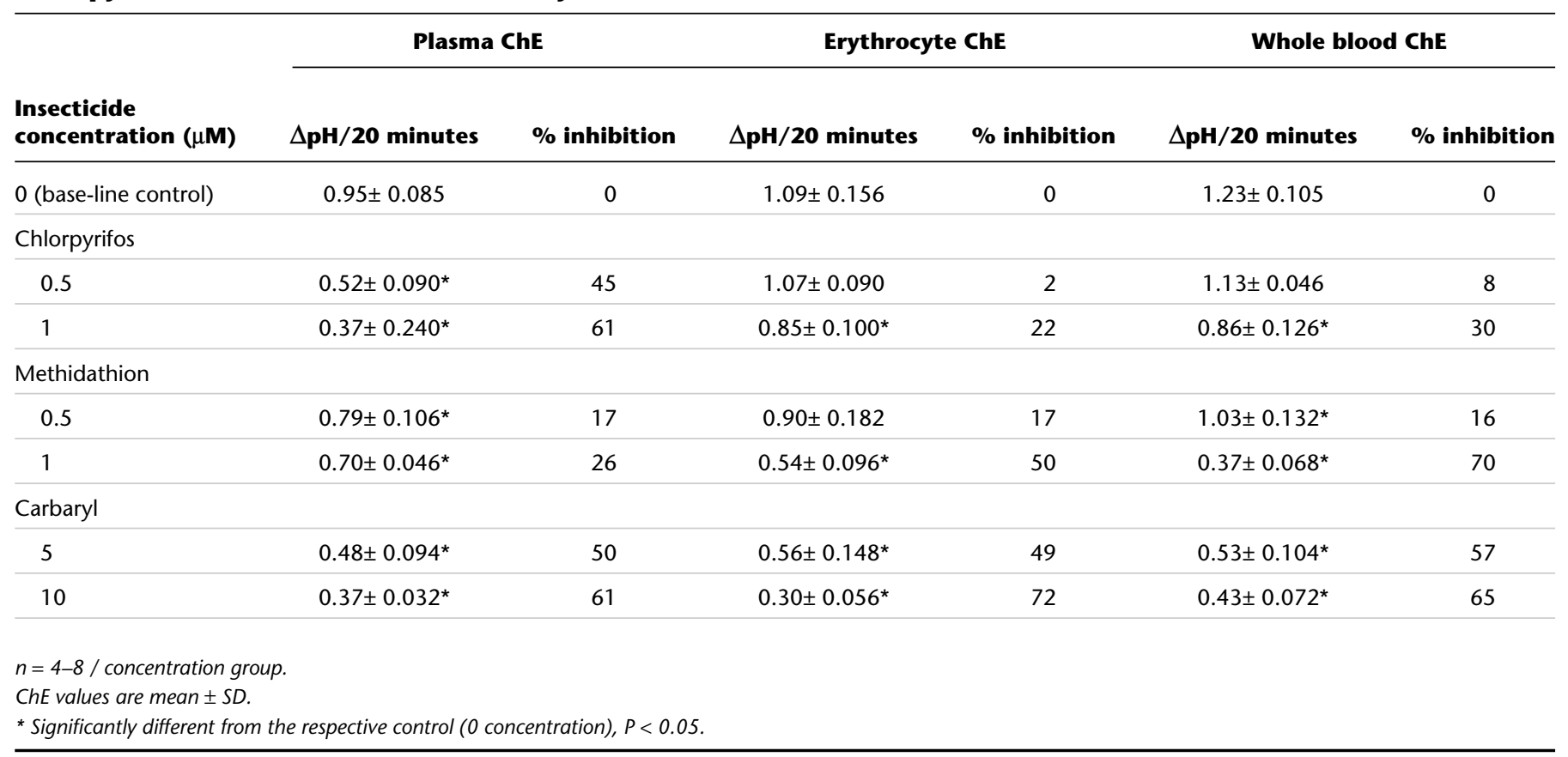


4. Singh B; Dogra TD; Tripathi CB. A study of serum cholinesterase activity in agricultural and industrial workers occupationally exposed to organophosphate insecticides. Int $J$ Med Toxicol 2002; 5 (2): 9.

5. Wilson BW; Henderson JD. Blood esterase determinations as markers of pesticide exposure. Rev Env Cont Toxicol 1992; 128: 55-69.

6. Wilson BW; McCurdy SA; Henderson JD et al. Cholinesterases and agriculture. Humans, laboratory animals, wildlife. In: Doctor BP (ed.). Structure and function of cholinesterases and related proteins. New York, NY: Plenum Press, 1998: 539-546.

7. Wilson BW. Clinical enzymology. In: Loeb WF, Quimby FW (eds.). The clinical chemistry of laboratory animals. Philadelphia, PA: Taylor and Francis, 1999: 399-454.

8. Kwong TC. Organophosphate pesticides: biochemistry and clinical toxicology. Therap Drug Mon 2002; 24 : 144-149.

9. Rusyniak DE; Nanagas KA. Organophosphate poisoning. Semin Neurol 2004; 24: 197-204.

10. Aygun D; Doganay Z; Altintop L et al. Serum acetylcholinesterase and prognosis of acute organophosphate poisoning. J Toxicol Clin Toxicol 2002; 40: 903-910.

11. Lotti M. Cholinesterase inhibition: complexities in interpretation. Clin Chem 1995; 41: 1814-1818.

12. Fairbrother A; Marden BT; Bennett JK; Hooper MJ. Methods used in determination of cholinesterase activity. In: Minneau P (Ed.). Chemicals in agriculture, Vol. 2. Cholinesterase-inhibiting insecticides. Amsterdam, The Netherlands: The Elsevier Science Publishers B.V., 1991: $35-72$.

13. Wills JH. The measurement and significance of changes in the cholinesterase activities of erythrocytes and plasma in man and animals. CRC Crit Rev Toxicol 1972; 1: 153-202.

14. Michel HO. An electrometric method for the determination of red blood cell and plasma cholinesterase activity. J Lab Clin Med 1949; 34: 1564-1568.

15. Nostrandt AC; Duncan JA; Padilla S. A modified spectrophotometric method appropriate for measuring cholinesterase activity in tissue from carbaryl-treated animals. Fund Appl Toxicol 1993; 21: 196-203.

16. Osweiler GD; Carson TL; Buck WB; Van-Gelder GA.
Clinical and diagnostic veterinary toxicology. 3rd ed. Dubuque, IA: Kendall Publishing Co, 1985: 298-317.

17. Williams $\mathrm{CH}$; Casterline JR Jr. A comparison of two methods of the measurement of erythrocyte cholinesterase inhibition after carbamate administration in rats. Food Cosm Toxicol 1969; 7: 149-151.

18. Mohammad FK; St Omer VEV. Modifications of Michel's electrometric method for rapid measurement of blood cholinesterase activity in animals: a minireview. Vet Hum Toxicol 1982; 24: 119-121.

19. Mohammad FK; Faris GA-M; Al-Kassim NA. A modified electrometric method for measurement of erythrocyte acetylcholinesterase activity in sheep. Vet Hum Toxicol 1997; 39: 337-339.

20. Ahmed OAH; Mohammad FK. A simplified electrometric technique for rapid measurement of human blood cholinesterase activity. Internet J Toxicol 2005; 2 (1).

21. Al-Baggou' BKh; Mohammad FK. Antagonism of methomyl-induced toxicosis by diphenhydramine in rats. Environ Toxicol Pharmacol 1999; 7: 119-125.

22. Mohammad FK; Al-Baggou B. Electrometric cholinesterase determination in poultry treated with dichlorvos and carbaryl. Online J Vet Res 2005; 9: 1-5.

23. Abass KS; Mohammad FK. Validation of an electrometric method for cholinesterase measurement in the plasma and tissues of the chicken. Proceedings of the 11th Scientific Congress, Faculty of Veterinary Medicine, Assiut University, Assiut, Egypt, December 5-7, 2004; 1: 241-259.

24. Alias AS; Mohammad FK. Electrometric measurement of plasma and tissue cholinesterase activities of four wild birds in Iraq. J Biol Res 2005; 4: 197-202.

25. Al-Jobory MMH; Mohammad FK. Validation of an electrometric blood cholinesterase measurement in goats. J Vet Sci 2005; 6: 299-303.

26. Coles EH. Veterinary clinical pathology. Philadelphia, PA: Saunders Co, 1986: 12-27.

27. Petrie A; Watson P. Statistics for veterinary and animal science. Oxford: Blackwell Science Ltd, 1999.

28. Mohammad FK; Faris GA-M; Alias AS; Al-Baggou' BKh. Blood cholinesterase activities in cattle, sheep and goats measured by a modified electrometric method. J Anim Vet Adv 2005; 4: 923-926. 